\title{
Strategies for Success in Human Development
}

\section{GUSTAV RANIS and FRANCES STEWART}

Gustav Ranis is Professor of International Economics and the Director of the Center for International and Area Studies, Yale University, and Frances Stewart is Professor of Development Economics and the Director of Queen Elizabeth House, University of Oxford

\section{In troduction}

Human development (HD) is defined as the improvement of the human condition so that people live longer, healthier and fuller lives. In the development of the concept of HD under the leadership of Mahbub ul Haq, some aspects of HD were related to people's physical well-being, such as health, nutrition and education, and others to the widening of choice and enhanced empowerment, including participation, political freedoms and cultural aspects. While we recognize the importance of both dimensions, this paper will be restricted to the physical aspects of HD. As a review of any of the United Nations Development Programme Human Development Reports (HDRs) indicates, country performance has differed considerably across both developed and developing countries. Our analysis will be concerned with explaining such divergence among developing countries. The focus is on developing countries partly because of the concentration on the material aspects, which weigh more heavily there, and partly because we believe somewhat different considerations apply in developed countries. The paper aims to identify the main elements of successful developing country performance in HD and arrive at some conclusions for policy, in the light of 10 years of experience in analyzing HD in the HDRs.

The next section will analyze the main contributory elements for sustained success in HD, based on previous work (Ranis et al., 1999). In that earlier paper, we conceptualized the links between economic growth (EG) and HD as forming two chains, one from EG to HD, and the other from HD to EG; we identified the important links in each chain and surveyed some of the empirical literature indicating their strength. We shall review some of the findings of that paper, as they provide necessary background for analyzing successful HD strategies. The subsequent section will identify some countries that have been successful performers in HD over the period 1960-1995 and explore which were the main elements contributing to this outcome. The final section will present the elements of successful performance and suggest some policy conclusions. 


\section{Basic framework for identifying conditions for success}

For the material side of $\mathrm{HD}$, the use of economic resources is essential. Hence, a society's total command over economic resources (Gross National Product (GNP)) provides the source of HD achievements in this dimension. However, the way economic resources are distributed and allocated can lead to very different HD performance for any given macro-economic achievement (i.e. level or growth in GNP per capita). To understand the success of HD, therefore, we need to explore how economic resources translate into HD achievements, as well as the determinants of the changing resource base to which HD performance itself makes an important contribution. We also need to consider the factors determining the sustainability of any HD achievement over time, which will include the continued growth of the underlying resource base.

\section{How economic resources translate into $H D$}

GNP contributes to HD mainly through household and government activity; civil society, for example, through community organizations and other non-governmental organizations (NGOs), also plays a role. The same level of GNP can lead to very different performance in HD according to the allocation of GNP among and within these institutions, and variations in their contribution to HD.

We find it helpful to differentiate two types of poverty: Private Income Poverty (PIP), which arises among households that have inadequate disposable income; and Social Income Poverty (SIP), which arises among households that have inadequate access to publicly provided goods and services.

When levels of PIP are high, either because national income per head is low or because it is badly distributed, the expenditure of the majority of households on HD is bound to be low. Large differences in poverty levels arise from the variation in the level and distribution of GNP per capita across societies. While evidence (for example, Fields, 1989; Deininger and Squire, 1996) indicates that, in general, PIP is reduced with economic growth, the extent of the reduction varies greatly with the distribution of income and its change over time. ${ }^{1}$ The way in which growth translates into income distribution and poverty reduction depends on the nature of the growth process - in particular, the extent to which it is based on the generation of employment and on increasing rural incomes. If the output mix is labour intensive and rural incomes rise rapidly, income distribution is more likely to improve and poverty reduction to occur than if growth is urban biased and capital intensive (Lipton, 1977; Stewart, 1977; Ranis, 1979).

For a given GNP, a more equal distribution of incomes received by households will lead to lower PIP, which is likely to result in better performance on HD, since poor households are more deficient in HD elements and are likely to spend more of their disposable income on items 
that contribute directly to improvement in HD, e.g. food, education and health.

As we would expect, empirical evidence shows that expenditure on HD-related items is strongly affected by the rate of poverty reduction. For example, if poor households receive extra income, they increase their food expenditure and calorie consumption significantly. Of 38 studies in different countries, one-third indicate that at least one-half of additional income is spent in this way (Strauss and Thomas, 1995). Empirical evidence also points to the positive effects of family income change on child schooling (for example, Birdsall, 1985; Behrman and Wolfe, 1987a,b; King and Lillard, 1987; Deolalikar, 1993; Alderman et al., 1996). While the evidence on the relations between income and health is less extensive than for education, studies suggest that household income also has a significant effect on the use of health services (Harbert and Scandizzo, 1982; Blau, 1986; Thomas et al., 1990, 1991, 1992), some showing a much higher relative response for low than for high-income households (Gertler et al., 1987).

Another important element determining how economic resources translate into $\mathrm{HD}$ is the extent of female control over income. For example, among households in the Gambia, the Philippines, and Cote D'Ivoire, the larger the proportion of food under women's control, the larger household calorie consumption, and the smaller the share of expenditure on other items (von Braun, 1988; Garcia, 1990; Hoddinott and Haddad, 1991).

Parallel to PIP, SIP, i.e. lack of access to essential HD-related public goods, is a key element in determining HD performance. The allocation of government resources to improving $\mathrm{HD}$ depends on the total level of public-sector expenditure, on how much of this flows to the HD sectors, and on the way in which it is allocated within these sectors. This can be expressed in the form of three ratios (see United Nations Development Programme, 1991): the public expenditure ratio, defined as the proportion of GNP spent by the various levels of government; the HD allocation ratio, defined as the proportion of total government expenditure going to the HD sectors; and, finally, the HD priority ratio, defined as the proportion of total HD-sector expenditure going to 'priority areas'. The precise definition of what constitutes a 'priority area' will inevitably vary according to a country's stage of development, rendering this third ratio more arbitrary and difficult to measure than the other two. However, within the HD sectors, some expenditures are clearly much more productive in terms of achieving advances in HD than others; for example, basic education, especially at an early stage of development, is generally recognized to have a larger impact on HD than tertiary education. There exist very large variations across countries in each of these ratios, which means that the same level of GNP may be associated with very different levels of government spending on HD priorities (see United Nations Development Programme, 1991, Chapter 3, 1996, Chapter 3).

The underlying determinants of these three ratios are complex, but include the following: (a) the tax capacity of the system; (b) the strength of 
the demand for military expenditure and for other non-HD priorities of the government; and (c) governments' responsiveness to the needs of lower income groups. All three factors are greatly influenced by the prevailing political economy, which includes the historically determined power of different interest groups, bureaucratic objectives, capacity and structures, as well as the strength of popular pressures.

It should be noted that all three ratios are affected by the extent of decentralization of government. Decentralization tends to increase the total revenue available because of enhanced local tax efforts; it is likely to raise the HD allocation ratio and to improve the HD priority ratio since local governments often consider human development objectives more important than central governments. Decentralization of publicly provided services has been introduced recently in a wide range of countries. Tentative conclusions about its effectiveness are mixed, with apparent relative success in promoting efficiency and contributing to HD in Argentina, Bolivia, Indonesia and Karnataka in India, but less so in Bangladesh and Brazil. However, in most cases, local governments have been severely constrained in their ability to raise taxes as well as in the freedom of allocative decision-making; and full democratic devolution has been rare (see Ranis and Stewart, 1994; Behrman, 1995b; Prud'homme, 1995; Klugman, 1995).

The significance of public expenditure choices for improving HD is illustrated by a comparison between Kenya and Malawi. In the 1980s, a similar proportion of national income went to public expenditure (27\% in Kenya; $30 \%$ in Malawi), but Kenya had a significantly higher social allocation ratio ( $47 \%$ compared with $35 \%)$ and social priority ratio (34\% compared with 14\%), so that the proportion of GDP going directly to HD-improving activities in Kenya was over three times that of Malawi $5.1 \%$ compared with 1.5\%) (United Nations Development Programme, 1996, p. $71^{2}$ ).

The importance of economic growth for raising public-sector expenditures on promoting HD is illustrated by a comparison between Botswana and Sudan. Starting with similar levels of per-capita expenditure on health and education in 1970, rapid economic growth in Botswana from 1970 to 1992 led to a fast rise in social expenditure, while social expenditure in Sudan hardly changed, as there was economic stagnation. By 1992, social expenditure in Botswana was four times as high as in Sudan.

Finally, the NGO or other civil society activity, on which information is more scattered, is typically heavily oriented towards HD objectives (e.g. education, nutrition and health). Resources are derived from private donations and increasingly from government, in each case including both foreign and domestic sources. There are considerable variations in the extent, vitality and effectiveness of NGO activities across countries, depending on their history, culture, tax laws and actual or perceived government deficiencies in providing services. In most contexts, NGOs play a supplemental or even marginal role, but in a few areas - for example, BRAC and the Grameen Bank in Bangladesh, the Harambee Schools in Kenya and the 'Comedores Populares' in Peru - they appear to represent a major source of HD enhancement (Riddell et al. 1995). 
Expenditures on HD inputs are clearly not objectives in themselves, but rather constitute instruments for achieving advances in various dimensions of basic well being. A further important determinant of HD achievements is, therefore, the effectiveness of these expenditures in raising HD levels, i.e. what type of provision is most productive at what level of development, and how different combinations effect a change in HD. In our earlier work, we termed this relationship the Human Development Improvement Function (HDIF) (Ranis et al., 1999). These relationships are similar to those of a production function in that they relate the inputs into HD, such as public expenditure on health services or water, to HD improvement. An illustration of the type of relationship involved is whether and how far the provision of safe water is complementary to or substitutes for education in contributing to improvements in health. The relationships here are complex, depending on individual and community behaviour and the existence of local knowledge about relevant technologies. Empirical work looking into these relationships has provided abundant evidence that education, especially female, tends to improve infant survival and child nutrition, as does female control over household income (see, for example, Rosenzweig and Schultz, 1982; Wolfe and Behrman, 1987; Barrera, 1990; Thomas, 1990; Strauss and Thomas, 1995).

It should be clear from this discussion of the various links between the economic resource base and HD achievements that while, in general, we would expect important causal connections to exist between the economy and HD achievements, these connections are not automatic: the strength of the links varies according to a large range of factors, including the structure of the economy, the distribution of assets and the policy choices made. The institutional heritage of the society affects these choices and the strength of links at each stage; when people act together to promote their well-being, when public morality is high, when the community monitors malfeasance, and when it participates extensively in public life, ceteris paribus, we would expect all the links to be stronger, i.e. HD achievement is likely to be positively associated with the strength of social capital.

In summary, this review of the connections between resources and HD suggests that the links are likely to be stronger the lower PIP, which, for a given level of GNP per capita, means the more equally income is distributed; the more income households allocate to HD at a given income level, which may be related both to the level of female education and to female control over income within the household; the higher the proportion of GNP devoted to priority social expenditure by the government, and the lower SIP; the more effective the contribution of institutions, including community organizations and other NGOs; and finally, the more efficient the HDIF.

\section{Determinants of the resource base}

All these factors determine how well a country manages on HD for a given resource base, but clearly the size and growth of the resource base is 
critical. A large amount of theoretical and empirical literature has been devoted to 'explaining' variations in economic growth (for example, Denison; 1980; Jorgenson, 1988; Barro, 1991; Scott, 1992). Major results which are widely accepted are that the share of investment in GNP (which may be domestically or externally financed) is highly significant and that human capital makes an important contribution. Empirical investigations also indicate that a more equal distribution of income is associated with higher economic growth. Another factor, which would appear to be important in strengthening all the links already mentioned, although it is much more difficult to identify empirically, is the effectiveness of economic policy.

The important contributory role of human capital represents the main feedback running from HD achievement to economic performance. Abundant evidence for this feedback comes both from micro-studies and macro-regressions.

At a micro-level, numerous studies indicate that increases in earnings are associated with additional years of education, with the rate of return varying with the level of education (see surveys in Behrman and Deolalikar, 1988; Schultz, 1988, 1993a,b; Behrman, 1990a,b,c, 1995a; King and Hill, 1993; Psacharopolous, 1994; Strauss and Thomas, 1995). While social rates of return (which deduct the publicly financed costs of education but make no other adjustments to the private returns) are below the private returns, they are still typically greater than returns to most physical investment. The returns to primary schooling tend to be greater than the returns to secondary and tertiary education. ${ }^{3}$ In agriculture as well, evidence suggests positive effects of education on productivity among farmers using modern technologies, but less impact, as might be expected, among those using traditional methods (Welch, 1970; Schultz, 1975; Jamison and Moock, 1984; Birdsall, 1993; Foster and Rosenzweig, 1994; Rosenzweig, 1995; Behrman et al., 1995).

Improved health and nutrition have been shown to have direct effects on labour productivity, especially among poorer individuals (see surveys in Behrman, 1993, 1996). A range of labour productivity gains has been observed associated with calorie increases (see Cornia and Stewart, 1995), including studies of farmers in Sierra Leone, sugar cane workers in Guatemala and road construction workers in Kenya (Immink and Viteri, 1981; Wolgemuth et al., 1982; Strauss, 1986); a study of Cali, Colombia found that a health and nutrition programme increased the lifetime earnings of individuals to from 2.5 to 8.9 times those of an illiterate worker (Selowsky, 1981). In some contexts, the evidence indicates even larger productivity effects arising from health and nutrition than from formal schooling, although the impact of education has been much more emphasized in the development literature.

From a macro-perspective, the 'new growth theories' aim to explain growth by incorporating some of these same effects, emphasizing education as well as learning and research and development (R\&D). According to Lucas (1988), for example, the higher the level of education of the work- 
force, the higher the overall productivity of capital because the more educated are more likely to innovate, and thus affect everyone's productivity. In other models, a similar externality is generated as the increased education of individuals raises not only their own productivity, but also that of others with whom they interact, so that total productivity increases as the average level of education rises (Perotti, 1993; see also Roemer (1990) and Grossman and Helpman (1991), who focus on the role of education and R\&D). A number of empirical studies supporting these models have shown the positive effect of education on economic growth at a macro level, with its size varying according to the measure of education and the particular growth model adopted (for example, Barro, 1991; Barro and Lee, 1993, 1994).

In summary, the growth of economic resources is an important contributor to the enhancement of the material aspects of HD. Significant determinants of this growth include the investment rate, the distribution of income, the policy setting, and the level and character of HD achieved previously.

\section{Sustainability of HD improvements}

Sustainability of achievements in HD is clearly an important aspect of success. To a certain extent, HD achievements are self-sustaining, as, once people have attained certain levels of health and education, they tend to make every effort to maintain this over the next generation. Moreover, once basic advances have been made, for example in life expectancy, it may take fewer resources to sustain them. Nonetheless, over the past 30 years, several countries succeeded in improving their HD quite impressively, but were unable to continue to make progress, and some even slipped back.

Reasons for lack of sustainability have their main roots in a reversal of one or another of the basic reasons for success: namely, undermining of the economic resource base and/or changing the allocation of resources away from HD.

Countries may be in a virtuous cycle of achievement, with growth of resources supporting improvement in $\mathrm{HD}$, which, in turn, reinforces further economic growth. Conversely, some may be in a vicious cycle, with failures on both HD and economic growth. In some cases, 'lopsided' performance can be observed, with success in one dimension but failure in the other, at least for a time. We define success on $\mathrm{HD}$, but below average performance on economic growth, as HD-lopsided, while rapid economic growth accompanied by stagnant HD is called EG-lopsided.

Taking a three-decade period, our earlier work showed that neither type of lopsidedness was found to persist in the long run. The evidence indicated that countries may move from HD-lopsidedness to a virtuous cycle, but no country succeeded in moving from EG-lopsidedness into a virtuous cycle. This gives strong support to the view that a country cannot rely exclusively on an economic growth strategy, while neglecting HD improvements, to achieve a virtuous cycle. However, the fact that virtually no country (with just one exception; the exception being Costa Rica, which 
remained in the HD-lopsided category for all three decades) remained in a HD-lopsided position over three decades indicates that sustainability of HD requires supporting economic performance over the long term.

\section{Empirical evidence of successful country performance}

\section{Identifying successful countries}

While the links between EG and HD elucidated in the previous section appear to be significant, it is our intent here to examine which links proved particularly important in determining notably successful country performance. In this section, we explore the behaviour of the countries that were most successful in HD over the period 1960-1995, and examine the main contributory factors. We shall also identify which countries sustained successful HD performance and which fell back over the decades, and examine the conditions favouring sustainability.

Before identifying examples of countries that have succeeded in HD, we need to determine the criteria of success to be used. The Human Development Index (HDI) adopted in the HDRs encompasses education, life expectancy and 'adjusted income', with the precise definition and methodology underlying the HDI changing over time. While it has clearly performed an important role in focusing attention on $\mathrm{HD}$ and country differences, it remains somewhat arbitrary. Rather than use the HDI, in this paper, we shall, therefore, adopt two very reductionist proxies for HD achievement: namely, life expectancy (LE) and infant mortality rate (IMR). One reason for the choice of $\mathrm{LE}$ is the simplicity of the measure, which means that no arbitrary weighting is required; another is that LE is the prerequisite for enjoyment of any other dimension of the good life; third, it is highly correlated with the education components of HDI. Although LE is not a very discriminating indicator for rich countries, it exhibits large variations for developing countries, which are our concern here. We have supplemented LE with IMR partly because of measurement problems with LE in between census years, and partly because of IMR's greater sensitivity to change. However, we recognize that there are severe limitations arising from confining our measurement of HD to LE and IMR; in particular, by excluding all non-material aspects, we admittedly bias our analysis and policy conclusions.

Our concern is with the period 1960-1995. Several criteria for what is meant by 'success' can be advanced. One criterion for success is ranking achievements in the level of HD attained by 1995. This is the product of two elements: the historically given 'initial' achievements in 1960, and progress between 1960 and 1995 which is a second criterion. Other possible criteria relate HD achievement to economic performance. While economic growth is a major contributor to HD achievement, as already explained, some countries do particularly well in relation to their economic record. To capture this, two other indicators could be advanced: one relating levels of HD achievement in 1995 to levels of GDP per capita in the same year, and 
the other relating change in HD to change in income per capita, 1960-1995. The four indicators are set out in Table 1.

TABle 1. Four possible indicators of success in HD

A. 1995 HD level

B. 1960-1995 HD progress
C. 1995 HD level in relation to 1995 GDP per capita

D. 1960-1995 progress in HD in relation to growth in incomes per capita

We believe it is absolute achievements in HD that matter, rather than achievements relative to economic performance, so that $\mathrm{C}$ and $\mathrm{D}$ in Table 1 are of somewhat less interest. Moreover, we prefer indicator B to A, i.e. progress between 1960 and 1995, which we measure in terms of the shortfall reduction over the period, i.e. changes in the percentage of deficiency of the country's level of performance relative to the 'frontier' or best performing country (see United Nations Development Programme (1995) for more details). The reason for our preference is that, to the extent that 1995 achievement is influenced by the 1960 levels, there is little that can be done about these initial conditions, given that policy can only affect changes. Nonetheless, we are also interested in countries whose main success lies in their experience at an earlier stage because the historical influences that account for the earlier performance continue to have a long-term impact, as well as containing lessons for policy.

From a global perspective, the ten best performers on all four criteria are presented in Table 2 with both LE and IMR adopted for criteria B. The IMR tends to be a more sensitive and often more reliable measure than LE, even though LE is generally preferred as an indicator of HD, as it encompasses the whole population. Of the ten, eight are among the best performers on both indicators, pointing to the high level of correlation between them. China and Saudi Arabia appear on the LE shortfall reduction improvement list only, while Cuba and Jamaica appear only on the IMR improvement list. It seems plausible that this may have been due to the

TABLE 2. Global best performers

\begin{tabular}{lllll}
\hline A. LE 1995 & $\begin{array}{l}\text { B. LE shortfall } \\
\text { reduction, } \\
1960-95\end{array}$ & $\begin{array}{l}\text { B. IMR shortfall } \\
\text { reduction, } \\
1960-96\end{array}$ & $\begin{array}{l}\text { C. LE in relation } \\
\text { to GDP ranking }\end{array}$ & $\begin{array}{l}\text { D. LE/GDP ranking } \\
\text { changes, 1960-95 }\end{array}$ \\
\hline Singapore & Costa Rica & Singapore & Cuba & Nicaragua \\
Costa Rica & Singapore & Korea & Madagascar & Madagascar \\
Cuba & UAE & Oman & Congo & Honduras \\
Kuwait & Chile & Chile & Jamaica & Jamaica \\
Chile & Kuwait & UAE & Sri Lanka & El Salvador \\
UAE & Oman & Cuba & Vietnam & Peru \\
Jamaica & S. Arabia & Malaysia & Honduras & Venezuela \\
Panama & Korea & Kuwait & Myanmar & Costa Rica \\
Trin. and Tob. & China & Jamaica & El Salvador & Trin. and Tob. \\
Uruguay & Malaysia & Costa Rica & Haiti & Mexico \\
\hline
\end{tabular}


repercussions of the one child policy in China and the highly targeted infant health programmes in Cuba and Jamaica.

Only two countries, Cuba and Jamaica, appear both as the best absolute performers on LE and in relation to GDP. Countries which had particularly good performance on LE in relation to GDP, but not on LE as such, are countries with relatively weak economic performance, which nevertheless maintain some focus on HD - such as Tanzania, El Salvador and Madagascar. Similarly, comparing improvement in LE with improvement in LE in relation to economic growth, we find that four countries are on both lists (Costa Rica, Honduras, Jamaica and Cuba), but a number of others do well on LE improvement only in relation to their growth performance - for example, Mexico, Nicaragua, and Peru.

All the countries which showed the best improvements in LE and/or IMR, 1960-1995, clearly showed sustained performance as indicated by an outstanding achievement over the entire 35-year period. Analysis of the best ten performers decade by decade over the same period showed that, of the countries that were in the top ten with respect to life expectancy reduction in the 1960s, only three were among the best performers in 1980-1995 (Kuwait, UAE and Costa Rica). However, there was more consistency in improvements in IMR, with six of the best performers in 1960-1970 in the top ten in 1980-1995. Countries which 'dropped out' of the best performing IMR list were Kuwait, China, Cuba, Venezuela, Panama and Jamaica, all societies which experienced either particular economic difficulties or major switches in social policy during the latter period.

The global best performers include countries from the Middle East, Asia and Latin America, but none from Sub-Saharan Africa. However, in order to analyze the major factors involved in success, it is more useful to take a regional perspective because of regionally based differences in constraints and opportunities. Hence, our more detailed analysis will be at the regional level, focusing on Africa, Asia, and Latin America and the Caribbean. We do not analyze Middle Eastern countries further, since the success of some countries there (UAE, Oman, Kuwait and Saudi Arabia) is mainly based on abundant oil revenue, which makes them rather atypical for comparative analysis.

Turning to the regional country performance, Table 3 shows the four best performers according to levels of life expectancy in 1995, infant mortality in 1996, and shortfall reduction in LE and IMR, 1960-1995.

In the African case, there is a considerable difference among the four indicators. In fact, only one country, Mauritius, appears in all four lists. However, in the remaining regions, three out of four appear as best performers with respect to life expectancy in 1995, and improvements in life expectancy and infant mortality 1960-1996. In Asia, these are Singapore, Korea and Malaysia; in Latin America, Costa Rica, Chile and Cuba.

Looking at the performance decade by decade, we find that Mauritius, Korea and Costa Rica are among the four best in every decade and on both HD indicators. This points to consistency over time, i.e. the absence of oscillation in performance. In Asia, Singapore is consistently among the best 
TABLE 3. Regional best performers under criteria $\mathrm{A}$ and $\mathrm{B}$

\begin{tabular}{|c|c|c|c|}
\hline A. LE 1995 & A. IMR 1996 & $\begin{array}{l}\text { B. Shortfall reduction } \\
\text { in LE 1960-1995 }\end{array}$ & $\begin{array}{l}\text { B. Shortfall reduction } \\
\text { in IMR 1960-1996 }\end{array}$ \\
\hline \multicolumn{4}{|l|}{ Africa } \\
\hline Mauritius & Mauritius & Mauritius & Mauritius \\
\hline Lesotho & Botswana & Lesotho & Botswana \\
\hline Madagascar & Zimbabwe & Madagascar & Gambia \\
\hline Ghana & Namibia & Benin & Cameroon \\
\hline \multicolumn{4}{|l|}{ Asia } \\
\hline Singapore & Singapore & Singapore & Singapore \\
\hline Sri Lanka & Sri Lanka & Korea & Korea \\
\hline Korea & Korea & China & Malaysia \\
\hline Malaysia & Malaysia & Malaysia & Sri Lanka \\
\hline \multicolumn{4}{|c|}{ Latin America and the Caribbean } \\
\hline Costa Rica & Cuba & Costa Rica & Chile \\
\hline Cuba & Jamaica & Chile & Cuba \\
\hline Chile & Chile & Cuba & Jamaica \\
\hline Jamaica & Costa Rica & Honduras & Costa Rica \\
\hline
\end{tabular}

on infant mortality but in only two of the periods on LE improvement. In Latin America, Chile is among the four best on LE improvement for all three decades, and for IMR improvement for two of the sub-periods.

It is relatively easy, therefore, to select a sample for further investigation of the sources of success in Asia and Latin America, by choosing the three countries which appear on all four lists, and which are also consistently among the best over more than one decade - and adding Sri Lanka to the Asian sample and Jamaica to the Latin American sample because they appear on three out of the four lists of best performers. In the case of Africa, only Mauritius qualifies in terms of being on all four lists. The other countries we select in Africa are Madagascar and Lesotho, which appear on three out of the four best performing lists; we also include Botswana because it was among the best on IMR improvement and among the best on life expectancy in two of the three sub-periods.

In Table 4, we present the four best performers in each region according to criteria $\mathrm{C}$ and $\mathrm{D}$ (as defined in Table 1). In Africa, only Madagascar appears both as absolutely a best performer on criteria A and B as well as in terms of criteria C and D. In Asia, Sri Lanka appears in C and $\mathrm{D}$ as well as A. Likewise for Cuba and Jamaica in Latin America. The other countries which appear under $\mathrm{C}$ and $\mathrm{D}$, but not $\mathrm{A}$ or $\mathrm{B}$, seem a rather random selection of countries with poor economic performance - including Somalia, Nepal and Benin. Although criteria C and D undoubtedly do pick out some countries which have put a particular focus on HD (e.g. Tanzania, the Philippines, Nicaragua), the listing depends so much on collapsed economic performance that it confirms our decision to use only criteria A and B in choosing our sample of successful countries. In other words, relating HD performance to economic criteria rewards countries 
which have done very poorly on economic growth and whose HD performance has been good only in that relative sense.

\section{The behaviour of successful countries with respect to the major causal links}

In the second section, we identified the main elements conducive to success in HD. Table 5 provides evidence on the performance with respect to these elements in each of the countries just identified as successful. Behaviour is classified into very good $(++)$, good $(+)$, moderate $(0)$ and poor $(-)$. In classifying performance with respect to these various elements, we have compared these countries with developing countries as a whole. For example, any performance above the average of all developing countries is classified as good. The precise method of classification is indicated in the footnotes to Table 5. The causal elements examined include growth in real GDP per capita, income distribution as measured by the Gini Coefficient, the expenditure ratio, the social allocation ratio, primary and secondary education as a proportion of total educational expenditure (as an indicator of the priority ratio), social expenditure over GDP, and three measures of women's position, i.e. the female primary school enrolment ratio, the ratio of female to male primary school enrolment, and the female share of earned income. In general, we have tried to find data to represent the average performance over the entire period; but data problems have not always made this possible. Moreover, some variables, such as female primary enrolment can be expected to have a lagged impact.

TABLE 4. Regional best performers under criteria C and D

\begin{tabular}{|c|c|c|c|}
\hline $\begin{array}{l}\text { C. Ranking } \\
\text { difference } \\
\text { between GDP } \\
\text { per capita and } \\
\text { LE } 1995\end{array}$ & $\begin{array}{l}\text { C. Ranking } \\
\text { difference } \\
\text { between GDP } \\
\text { per capita and } \\
\text { IMR } 1995\end{array}$ & $\begin{array}{l}\text { D. Ranking difference between } \\
\text { GDP per capita growth and LE } \\
\text { changes, 1960-1995 }\end{array}$ & $\begin{array}{l}\text { D. Ranking difference } \\
\text { between GDP } \\
\text { per capita growth and } \\
\text { IMR changes } \\
1960-1996\end{array}$ \\
\hline \multicolumn{4}{|l|}{ Africa } \\
\hline Congo & Burkina Faso & Madagascar & Madagascar \\
\hline Tanzania & Gambia & Congo & Sudan \\
\hline Madagascar & Eritrea & Tanzania & Senegal \\
\hline Ethiopia & Tanzania & Ethiopia & Chad \\
\hline \multicolumn{4}{|l|}{ Asia } \\
\hline Sri Lanka & Vietnam & Nepal & Sri Lanka \\
\hline Vietnam & Sri Lanka & China & Nepal \\
\hline Myanmar & Philippines & Philippines & Malaysia \\
\hline China & India & Sri Lanka & Singapore \\
\hline \multicolumn{4}{|c|}{ Latin America and the Caribbean } \\
\hline Cuba & Cuba & Nicaragua & Jamaica \\
\hline Jamaica & Jamaica & Honduras & Nicaragua \\
\hline Honduras & Honduras & Jamaica & Honduras \\
\hline El Salvador & Nicaragua & El Salvador & Trinidad and Tobago \\
\hline
\end{tabular}




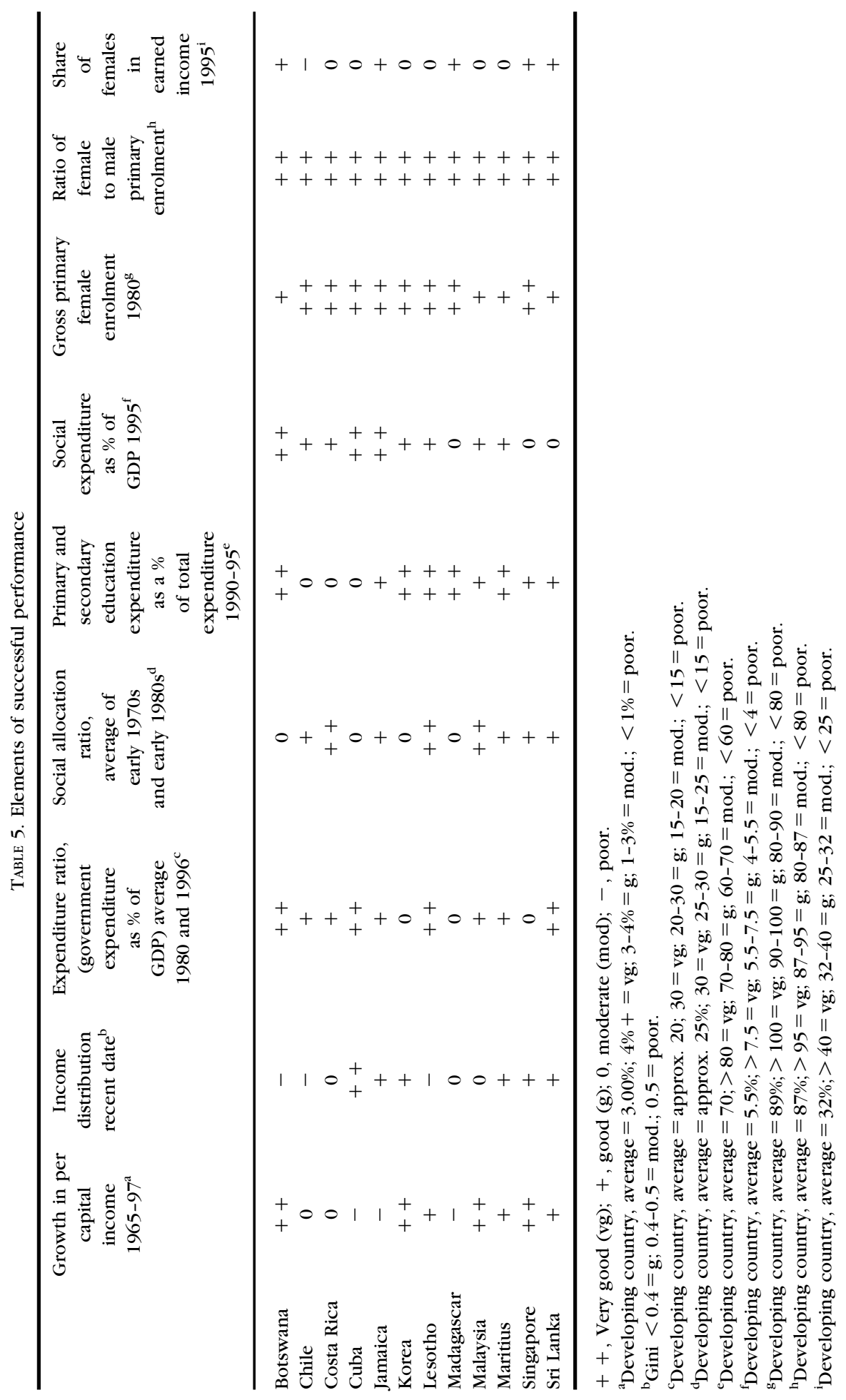


A glance at Table 5 shows considerable variance in performance on some variables - for example, on economic growth and income distribution. For other elements, there is much more homogeneity - this is especially notable with respect to the female primary enrolment ratio, which is invariably high compared with developing countries as a whole, and, particularly, the ratio of female to male primary enrolment, which was rated as 'very good' in every success case. We included the ratio of the female to male primary enrolment as well as the female primary school enrolment rate itself to check whether the latter was simply capturing high levels of primary school enrolment among both boys and girls, rather than female enrolment in particular. The fact that the results are stronger for the female/male enrolment ratio than even for female primary enrolment show that it is girls' education which is especially important for success in HD.

\section{Alternative explanations of success}

The information given in Table 5 allows us to explore alternative sets of causal factors responsible for success in the 12-country sample. None of the countries did outstandingly well on all the elements we identified as conducive to success. Rather, it appears that countries did particularly well with respect to some elements, which compensated for relative weakness elsewhere. The fact that countries do not need to be outstanding in all aspects should be encouraging to policy-makers trying to promote HD.

As noted earlier, economic growth provides a favourable environment for improving $\mathrm{HD}$, both through its effects on household and on social income (i.e. social sector expenditures by government). Among the 12 successful countries, in fact, growth performance was mixed, with some very high growth rates and some very poor. Moreover, not all countries had a particularly good income distribution. However, some conclusions emerge concerning alternative sets of factors combining to yield success.

1. One type of success was apparently based on high growth accompanied by good distribution, which permitted countries to succeed despite quite moderate but well-prioritized social expenditure. Korea was such a case, and Taiwan also (not included here because of data problems). For both Korea and Taiwan, early land reform was partly responsible for the good distribution of income.

2. Botswana and Malaysia also had very good growth, but less good distribution. This was compensated for by a good expenditure ratio, also accompanied by a good priority ratio.

3 . Singapore is another case with very good growth and moderate income distribution, but in this case with only moderate expenditure ratios, although this was apparently offset by very high female primary enrolment rates and a high female share of earned income.

4. Mauritius and Sri Lanka represent cases where good distribution, and good and well-allocated social expenditure compensated for growth that was good but not spectacular. 
5. Lesotho is a case with good growth but poor distribution, accompanied by a very good expenditure ratio, a good priority ratio and a very good female primary enrolment ratio.

6. Chile and Costa Rica exhibit moderate growth, but not good distribution (better in the case of Costa Rica than Chile), and good and well-allocated social expenditure ratios, leading to very effective and comprehensive social programmes. Both countries also had very good female enrolment ratios.

7. Cuba, Jamaica and Madagascar are particularly interesting cases because growth was poor in each case. In the case of Cuba, success seems to have been achieved, nonetheless, by good distribution, high and wellallocated social expenditures, as well as high female enrolment ratios. Jamaica seems to have managed without such a good distribution but with a large female share of earned income, and otherwise similar characteristics. In Madagascar, not only was growth poor, but social expenditure ratios were also quite low; this poor combination was, it seems, rescued by unusually good priority ratios, high female primary enrolment ratios and a high share of female earned income.

The differing economic and social choices just reviewed are clearly the outcome of differing political decisions, as well as economic capability. All the successful countries showed political commitment to improving HD, but for somewhat different reasons. Some were primarily motivated by the desire to increase growth, regarding $\mathrm{HD}$ as an essential input towards this end, in the absence of natural resources, e.g. Korea, Singapore and Chile. ${ }^{4}$ These countries were not democratic for much of the period under observation. In contrast, some countries were social democracies, aiming to improve $\mathrm{HD}$ as a central objective, and providing state services in order to do so, e.g. Jamaica and Sri Lanka. In a more extreme version, Cuba, as a communist country, had similar objectives. Malaysia was a more complex case, where a prime objective was to raise the level of incomes and education of the Malays.

\section{Sustainability}

Clearly, a major issue is the question of the sustainability of success. Sustainability partly depends on technical possibilities, and partly on political choices. The fact that our sample was chosen as the set of countries that did best over a 35-year period indicates that their pattern of achievement has proved sustainable until now. The findings just presented about the features that account for success in each case show that in some countries success is highly dependent on one aspect (e.g. economic growth), and in some countries on another (e.g. the social expenditure ratio). In each case, continued success may be threatened if the particular element on which success depends is weakened: for example, with the 1997 financial crisis, growth rates in Korea and Malaysia were severely affected, at least temporarily. In Cuba and Jamaica, success was based on social and political 
TABLE 6. Best regional performance over three sub-periods in life expectancy shortfall reduction

\begin{tabular}{llll}
\hline Region & $1960-1970$ & $1970-1980$ & $1980-1995$ \\
\hline \multirow{2}{*}{ Africa } & Uganda & Botswana & Mauritius \\
& Benin & Mauritius & Madagascar \\
& Botswana & Cote D'Ivoire & Ethiopia \\
& Mauritius & Kenya & Gabon \\
Asia & China & Korea & Singapore \\
& Vietnam & Vietnam & Korea \\
& Malaysia & Singapore & Thailand \\
& Korea & Malaysia & Indonesia \\
& Cuba & Costa Rica & Chile \\
Latin Am erica and the Caribbean & Costa Rica & Chile & Costa Rica \\
& Jamaica & Cuba & El Salvador \\
& Venezuela & Panama & Honduras \\
\hline
\end{tabular}

models (involving among other things, high social expenditure ratios); these models appear to be in transition so that sustainability may become an issue. In all such cases, however, it is possible that other compensating factors can come to the rescue: for example, economic growth could accelerate in Cuba and Jamaica, offsetting reductions in social expenditures, as happened over the last two decades in Chile.

Another instructive way of looking at the issue of sustainability is to trace performance decade by decade, identifying which countries sustained their good performance and which dropped out. This exercise is performed in Table 6 for life expectancy by region (again using shortfall reduction as our measure).

Among the African countries, Uganda and Benin appear as best performers from 1960 to 1970 , but not in the subsequent decades. In Uganda, civil war was primarily responsible, and in Benin, civil disturbances. In Asia, China and Vietnam were included among the four best performers in the early decade. China did not appear again, probably because of cuts in the social services, especially health, associated with its changing economic model. Vietnam continued to be among the top four in the 1970 s but fell to 18th out of 20 in the 1980-1995 period, with similar factors probably at work. In Latin America, Venezuela was among the best performers in the 1960s. Poor governance, elitist policies and the declining oil prices over the 1980-1995 period were responsible for non-recurrence.

\section{Main conclusion $s$}

We should re-emphasize that we picked our success sample regionally, and that the African cases, in particular, would not have appeared in a global list, 
but also that, in assessing the elements relevant to their success, we still did apply average developing country performance standards.

We recognize that reducing all of the HD objectives to life expectancy and infant mortality eliminates many other important dimensions, which Mahbub ul Haq introduced into the Human Development Reports over time. Nonetheless, some of the elements that we do find are important instruments for achieving HD, e.g. enhancing the role of women, are also important aspects of a more comprehensive HD objective. Bringing these other dimensions of HD back into the picture would greatly enrich both the analysis and policy conclusions, but it would also greatly complicate the task.

However, on our relatively reductionist canvas, some important conclusions emerge.

1. First, we should note that every successful country performed well with respect to a number of the causal elements. Although no country was successful in every element, several countries succeeded (i.e. showed good or very good performance) in seven out of the nine elements. Only Madagascar succeeded in no more than three elements - and, as noted, Madagascar was a success only when the regional classification is adopted and not at the global level. Therefore, it seems that simultaneous good performance on several elements is needed.

2. Second, there are a number of alternative combinations that can lead to success in HD; weakness in any one area, including low growth, can be overcome by strength elsewhere, for example, by a good distribution of income or a high social expenditure ratio. That is to say, if a weakness emerges in one element, countries can compensate by strengthening other elements.

3. Third, it seems clear that female primary enrolment ratios play an especially important role in every one of our success countries and should get priority attention from policy-makers. This is further strengthened by the strongly positive role in success played by the female/male enrolment ratio.

4. Fourth, governments' ability to raise revenue is potentially important for HD.

5. Fifth, re-allocation of the government budget to priority social expenditures can make a large difference.

Our analysis has shown that there exists a range of ways of achieving success in HD, and therefore no unique path. As already noted, the one seemingly necessary condition is a high female enrolment ratio. Beyond that, we can pick out three relatively important combinations of elements for success in HD performance. One is good growth, if accompanied by reasonably good distribution and social expenditure ratios; the second is moderate growth combined with good distribution and supportive social sector performance; and the third is a strong 
emphasis on social expenditures (well prioritized) that can even be combined with poor economic growth when accompanied by relatively good distribution.

\section{Acknowledgement}

The authors are grateful to Michael Wang for helpful research assistance.

\section{Notes}

1 Bruno et al. (1995), for example, in a study of 20 countries, show that a $10 \%$ increase in average income per capita, 1984-1993, was associated with a $20 \%$ fall in the proportion of people living on less than $\$ 1$ a day.

2 These calculations adopt a narrow definition of social priority expenditure, including pre-primary and first-level education plus primary health care.

3 Following the work of Psacharopolous (1994), the conclusion that the returns to education are highest for primary education has become part of the accepted wisdom; but, in fact, this is by no means always the case (see, for example, Schultz, 1993a,b). However, since secondary education necessarily requires prior attendance at primary school, the usual measures of returns to primary education which do not allow for this may understate the total returns.

4 In the case of Taiwan, the commitment to HD was associated with a desire to avoid the revolutionary events on the mainland.

\section{References}

Alderman, H., Behrman, J.R., Khan, S., Ross, D. and Sabot, R. (1996) 'The income gap in cognitive skills in rural pakistan', Economic Development and Cultural Change, 44.

Barrera, A. (1990), 'The role of maternal schooling and its interaction with public health programs in child health production', Journal of Development Economics, 32 (1).

Barro, R. (1991) 'Economic growth in a cross-section of countries', Quarterly Journal of Economics, 106.

Barro, R.J. and J.-W. Lee (1993) 'International comparison of educational attainment', Journal of Monetary Economics, 32.

Barro, R. J. and J.-W. Lee (1994) 'Losers and winners in economic growth', Proceedings of the World Bank Annual Conference on Development Economics 1993, IBRD, Washington, DC.

Behrman, J.R. (1990a) Human Resource Led Development: Review of Issues and Development, ARTEP/ILO, New Delhi, India.

Behrman, J.R. (1990b) 'The action of human resources and poverty on one another: what we have yet to learn', LSMS Working Paper 74, World Bank, Washington, DC.

Behrman, J.R. (1990c) 'Women's schooling and nonmarket productivity: a survey and a reappraisal', mimeo, University of Pennsylvania, Philadelphia, PA.

Behrman, J.R. (1993) 'The economic rationale for investing in nutrition in developing countries', World Development, 21.

Behrman, J.R. (1995a) 'The impact of distributive policies, governmental expenditure patterns and decentralization on human resources', mimeo, University of Pennsylvania, Philadelphia, PA.

Behrman, J.R. (1995b) 'Intra-household allocation of resources: is there a gender bias?', Sex Differentials in Infant and Child Mortality, Population Division, United Nations, New York.

Behrman, J.R. (1996) 'Impact of health and nutrition on education', World Bank Research Observer, 11. 
Behrman, J.R. and Deolalikar, A.B. (1988) 'Health and nutrition', in H.B. Chenery and T.N. Srinivasan (Eds), Handbook of Development Economics, Vol. 1, North Holland, Amsterdam.

Behrman, J.R. and Wolfe, B.L. (1987a) 'How does mother's schooling affect the family's health, nutrition, medical care usage and household?', Journal of Econometrics, 36.

Behrman, J.R. and Wolfe, B.L. (1987b) 'Investments in schooling in two generations in prerevolutionary Nicaragua: the roles of family background and school supply', Journal of Development Economics, 27.

Behrman, J.R., Rosenzweig, M.R. and Vashishtha, P. (1995) 'Location-specific technical change, human capital and local economic development: the Indian Green Revolution experience', in H. Siebert (Ed.), Locational Competition in the World Economy, Kiel Institute of World Economics, Kiel.

Birdsall, N. (1985) 'Public inputs and child schooling in Brazil', Journal of Development Economics, 18.

Birdsall, N. (1993) 'Social development is economic development', World Bank Policy Research Working Papers, WPS 1123, Washington, DC.

Blau, David (1986) 'Fertility, child nutrition, and child mortality in Nicaragua: an economic analysis of interrelationships', Journal of Developing Areas, 20.

Bruno, M., Ravallion, M. and Squire, L. (1995) 'Equity and growth in developing countries: old and new perspectives on the policy issues', paper presented at International Monetary Fund Conference on Income Distribution and Sustainable Growth, 1-2 June, Washington, DC.

Cornia, G.A. and Stewart, F. (1995) 'Two errors of targeting', in F. Stewart (Ed.), Adjustment and Poverty: Options and Choices, Routledge, London.

Deininger, K. and Squire L. (1996) 'A new data set, measuring income inequality', World Bank Economic Review, 10.

Denison, E.F. (1980) 'The contribution of capital to economic growth', American Economic Review, 70 (2).

Deolalikar, A.B. (1993) 'Gender differences in the returns to schooling and school enrollment rates in Indonesia', Journal of Human Resources, 28.

Fields, G.S. (1989) 'Changes in poverty and inequality in developing countries', World Bank Research Observer, 4.

Foster, A.D. and Rosenzweig, M.R. (1994) 'Technical change and human resources and investments: consequences of the Green Revolution', mimeo, University of Pennsylvania, Philadelphia, PA.

Garcia, M. (1990) 'Resource allocation and household welfare: a study of personal sources of income on food consumption, nutrition and health in the Philippines', Ph.D. thesis, Institute of Social Studies, The Hague.

Gertler, P., Locay, L. and Sanderson, W. (1987) 'Are user fees regressive? The welfare implications of health care financing proposals in Peru', Journal of Econometrics, 36.

Grossman, G.M. and Helpman, E. (1991) Innovation and Growth in the Global Economy, M.I.T. Press, Cambridge.

Harbert, L. and Scandizzo, P.L. (1982) 'Food distribution and nutrition intervention: the case of Chile', Staff Working Paper 512, The World Bank, Washington, DC.

Hoddinott, J. and Haddad, L. (1991) 'Household expenditures, child anthropometric status and the intrahousehold division of income: evidence from the Cote d'Ivoire', Discussion paper 155, Research Program in Development Studies, Woodrow Wilson School.

Immink, M. and Viterri, F. (1981) 'Energy intake and productivity of Guatemalan sugarcane cutters: an empirical test of the efficiency wage hypothesis', Journal of Development Economics, 9.

Jamison, D. and Moock, P. (1984) 'Farmer education and farm efficiency in Nepal: the role of schooling, extension services and cognitive skills', World Development, 12.

Jorgenson, D.W. (1988) 'Productivity and economic growth in Japan and the United States', American Economic Review, 78 (2). 
King, E.M. and Hill, M.A. (Eds) (1993) Women's Education in Developing Countries: Barriers, Benefits, and Policies, The Johns Hopkins University Press, published for the World Bank, Baltimore and London.

King, E.M. and Lillard, L.A. (1987) 'Education policy and schooling attainment in Malaysia and the Philippines', Economics of Education Review, 6.

Klugman, J. (1995) Decentralization: a survey of the literature from a human development perspective', Human Development Report Office Occasional Papers No. 12, United Nations Development Programme, New York.

Lipton, M. (1977) Why Poor People Stay Poor: Urban Bias in World Development, Temple Smith, London.

Lucas, R.E. (1988) 'On the mechanics of economic development', Journal of Monetary Economics, 22.

Perotti, R. (1993) 'Political equilibrium, income distribution, and growth', Review of Economic Studies, 60.

Prud'homme, R. (1995) 'The dangers of decentralization', The World Bank Research Observer, 10.

Psacharopolous, G. (1994) 'Returns to investment in education: a global update', World Development, 22.

Ranis, G. (1979) 'Appropriate technology in the dual economy: reflections on Philippine and Taiwanese experience', in A. Robinson (Ed.), Appropriate Technologies for Third World Development, MacMillan, New York.

Ranis, G. and Stewart, F. (1994) 'Decentralisation in Indonesia', Bulletin of Indonesian Economic Studies, 30.

Ranis, G., Stewart, F. and Ramirez, A. (2000) 'Economic growth and human development', World Development, 28.

Riddell, R., Robinson, M. de Coninck, J. Muir, A. and White, S. (1995) Non-Governmental Organizations and Rural Poverty Alleviation, Oxford University Press, New York.

Roemer, P.M. (1990) 'Endogenous technological change', Journal of Political Economy, 98.

Rosenzweig, M.R. (1995) 'Why are there returns in schooling?', American Economic Review, 85 (2).

Rosenzweig, M.R. and Schultz, T.P. (1982) 'Market opportunities, genetic endowments, and intrafamily resource distribution: child survival in rural India', American Economic Review, 72 (4).

Schultz, T.P. (1988) 'Education investments and returns', in H. Chenery and T.N. Srinivasan (Eds), Handbook of Development Economics, North Holland, Amsterdam.

Schultz, T.P. (1993a) 'Returns to women's education', in E.M. King and M.A. Hill (Eds), Women's Education in Developing Countries: Barriers, Benefits, and Policies, The Johns Hopkins University Press, published for the World Bank, Baltimore and London.

Schultz, T.P. (1993b) 'Investments in the schooling and health of women and men: quantities and returns', Journal of Human Resources, 28.

Schultz, T.W. (1975) 'The value of the ability to deal with disequilibria', Journal of Economic Literature, 13.

Scott, M. (1992) 'A new theory of endogenous economic growth', Oxford Review of Economic Policy, 8 (4).

Selowsky, M. (1981) 'Nutrition, health and education: the economic significance of complementarities at an early age', Journal of Development Economics, 9.

Stewart, F. (1977) Technology and Underdevelopment, Macmillan, London.

Strauss, J. (1986) 'Does better nutrition raise farm productivity?', Journal of Political Economy, 94.

Strauss, J. and Thomas, D. (1995) 'Human resources: empirical modeling of household and family decisions', in J.R. Behrman and T.N. Srinivasan (Eds), Handbook of Development Economics, Vol. 3, North Holland, Amsterdam.

Thomas, D. (1990) 'Intrahousehold resource allocation: an inferential approach', Journal of Human Resources, 25 (4).

Thomas, D, Strauss, J. and Henriques, M.H. (1990) 'Child survival, height-for-age and household characteristics in Brazil', Journal of Development Economics, 33. 
Thomas, D, Strauss, J. and Henriques, M.H. (1991) 'How does mother's education affect child height', Journal of Human Resources, 26.

Thomas, D., Lavy, V. and Strauss, J. (1992) 'Public policy and anthropometric outcomes in the Cote d'Ivoire', LSMS Working Paper 89, World Bank, Washington, DC.

United Nations Development Programme (1991), Human Development Report 1991, Oxford University Press, New York, NY.

United Nations Development Programme (1995), Human Development Report 1995, Oxford University Press, New York, NY.

United Nations Development Programme (1996), Human Development Report 1996, Oxford University Press, New York, NY. N.P. van Braun, J. (1988) 'Effects of technological change in agriculture on food consumption and nutrition: rice in a West African setting', Economic Development and Cultural Change, 37.

Welch, F. (1970) 'Education in production', Journal of Political Economy, 78.

Wolfe, B.L. and Behrman, J.R. (1987) 'Determinants of women's health status and healthcare utilization in a developing country: a latent variable approach', Review of Economics and Statistics, 56.

Wolgemuth, J. C., M. C. Latham, A. Hall and D. Crompton (1982) 'Worker productivity and nutritional status of Kenyan road construction laborers', American Journal of Clinical Nutrition, 36. 